\title{
Bate-bolas: rastros materiais de rupturas históricas nas fantasias dos mascarados cariocas
}

\section{Bate-bolas: material traces of historical ruptures in the costumes of the masquerades in Rio de Janeiro}

\author{
Nilton Gonçalves Gamba Junior, PUC-Rio \\ gambajunior@puc-rio.br \\ Priscila Andrade Silva, PUC-Rio \\ priscila.a.andrade@gmail.com
}

\begin{abstract}
Resumo
O presente artigo introduz a primeira fase do projeto de pesquisa Mascarados Afroiberoamericanos que coloca a pesquisa em Design em diálogo com os estudos etnográficos sobre mascarados da cultura popular. O estudo parte da obra de Luís Costa (COSTA, 2017) e reorganiza uma linha do tempo que relaciona diferentes manifestações de vários países para refletir sobre as relações entre a dimensão sagrada e profana por meio da análise formal das fantasias. Esta etapa de pesquisa tem como recorte o estudo dos Bate-bolas do Rio de Janeiro e o estudo comparativo com outras fantasias contemporâneas. A conclusão do trabalho demonstra a relevância da análise formal para uma tipologia das manifestações, para o mapeamento de influências históricas e para uma arqueologia das funções sociais desses ritos.
\end{abstract}

Palavras-chave: Mascarados, Fantasia, Cultura

\begin{abstract}
This paper introduces the first phase of the research project Mascarados Afroiberoamericanos that puts the Design research in dialogue with ethnographic studies on masquerades of popular culture. The study starts from the work of Luís Costa (COSTA, 2017) and reorganizes a timeline that relates different manifestations of various countries to reflect on the relationship between the sacred and profane dimension through the formal analysis of costumes. This research stage has as its focus the study of the Bate-bolas of Rio de Janeiro and the comparative study with other contemporary costumes. The conclusion of the work demonstrates the relevance of formal analysis for a typology of manifestations, for mapping historical influences and for an archeology of the social functions of these rites.
\end{abstract}

Keywords: Masquerades, Costume, Culture 


\section{Introdução}

O presente artigo descreve a primeira parte do projeto de pesquisa Mascarados Afroiberoamericanos que coloca em diálogo manifestações de mascarados da Península Ibérica, da África e da América Latina com o restante da Europa e Ásia. Nesta primeira etapa do projeto, a pesquisa recorta a observação dos Bate-bolas dos subúrbios do Rio de Janeiro em diálogo primeiramente com o percurso das influências europeias ${ }^{1}$.

A perspectiva do projeto é a contribuição da pesquisa em Design para os estudos etnográficos e objetiva ampliar a visibilidade da interferência material dentro das reflexões sobre cultura. Nesta direção, a análise de materiais, processos, resultados estéticos, simbólicos e a performatividade estruturam uma observação dos ritos culturais contribuindo para uma revisão histórica e antropológica.

O texto parte dos estudos de Luís Costa (2015) sobre a história das manifestações de mascarados na Europa. Costa é um brincante de Podence que delineia o percurso destes rituais desde o período Neolítico. Embora o seu objeto de estudo seja a análise específica dos Caretos de sua cidade, o autor organiza uma historiografia detalhada onde, não só propõe estudos sobre fluxos e rupturas, como consegue identificar as funções primordiais que interrelacionam diferentes manifestações.

Este artigo responde a duas questões específicas dentro do projeto que são: como utilizar a análise da materialidade como forma de refletir sobre questões históricas e antropológicas complexas? Que aspectos formais e perfomativos interferem na ruptura do cotidiano na passagem de ritos sagrados para um rito profano como os Bate-bolas cariocas?

\section{Mascarados, um fluxo historiográfico e geográfico}

Os estudos de Costa (2015) foram fundamentais para balizar a linha do tempo que elaboramos neste artigo ao produzir uma síntese dos principais marcos de expressão de brincantes mascarados para diversas manifestações europeias até as americanas contemporâneas. O ponto de partida de autor é o período Neolítico e a fixação do homem em sociedades agrárias.

A grande relevância dos estudos sobre o período Neolítico para a contemporaneidade é que vários aspectos sociais atuais foram fundados neste momento histórico. Para autores como Chang (CHANG, 1958), junto com a troca do estilo nômade pelo assentamento, se construiu várias dimensões sociais fundadoras como: a periodização das atividades em função das estações do ano, a ideia de patrimônio ou propriedade e a estruturação de papéis sociais mais

\footnotetext{
${ }^{1}$ O projeto está mapeando inicialmente mais duas manifestações além dos Bate-bolas: os Caretos de Podence e os Caretos do Recôncavo Baiano. Por conta deste recorte, a primeira fase do projeto de pesquisa Mascarados Afroiberoamericanos integra os departamentos de Design de quatro instituições de ensino: a Pontifícia Universidade Católica do Rio de Janeiro, o Instituto Politécnico de Leiria (IPL), a Universidade Federal do Recôncavo da Bahia (UFRB) e a Faculdade de Belas Artes da Universidade do Porto (U.Porto).
} 
complexamente segmentados, - aspectos diretamente ligados às funções ontológicas dos ritos de máscaras: a relativização de padrões identitários.

As máscaras surgem no hemisfério norte com os festivais invernais, especialmente no continente europeu e asiático. Os festivais invernais incluíam, em um primeiro momento, um conjunto de ritos místicos subjugados à produção econômica agrícola: inverno como período impróprio para plantio ou colheita. Assim como esta estação rigorosa rompia com o ciclo produtivo, se associava a ela a mudança de alguns padrões do assentamento comunitário - ainda que sempre gerando novos padrões pela própria periodicidade da manifestação.

Nestes primeiros ritos, os homens abrem o festival saindo da comunidade e partindo em direção às florestas. Só retornavam já cobertos de peles e mascarados com representações que poderiam remeter a animais relacionados a mitos de ascendência ou outras formas de entidades transcendentais. $\mathrm{O}$ disfarce permitia simultaneamente a ruptura com a identidade social do brincante e a modificação dos hábitos da aldeia - ainda que o gênero fosse determinante na ação, permitindo apenas a participação de rapazes, o anonimato da máscara era uma forma eficaz de rever a construção social de identidades.

Além das máscaras e das roupas de peles, Costa descreve que é comum encontrar alusões ao uso de um pedaço de animal, carcaça ou pele, ainda com sangue. Os jovens agora, com esses pedaços de animal, já de volta em suas aldeias, assustavam a todos e corriam atrás das moças para lhes bater com o objeto em uma brincadeira que trazia o outro gênero social para o ritual. $\mathrm{O}$ fim desta espécie de "pique" era uma autorização do grupo para entrada em um período de catarses coletivas que poderiam envolver excessos (alimentos, danças, sexo); novas regras (horários e hábitos); novas funções (místicas, lúdicas ou de expiação e contrição) e o estímulo e permissão para experimentação de novos estados de consciência (com uso de álcool ou outras substâncias ou práticas facilitadoras de uma nova experiência de consciência).

Neste artigo, selecionamos três principais rupturas destes ritos neolíticos com o cotidiano das outras estações e que se tornaram perenes na história para analisarmos os seus rastros na expressão material das fantasias de bate-bolas do subúrbio carioca: i) a ruptura com os hábitos cotidianos coletivos (novos hábitos e crítica aos hábitos anteriores); ii) a subversão da identidade do indivíduo (sigilo e anonimato do papel social); iii) ruptura com a forma de tomar consciência do entorno (novos modelos de percepção do coletivo e de si mesmo). Embora totalmente interligados, esses três aspectos trazem respectivamente a ruptura com o que faço, o que represento e como percebo os dois anteriores (o que faço e o que represento).

Acrescentando ao estilo de vida gregária a fundação de experiências particulares de igualdade, equidade e desigualdade, o livro Pathways to Power (PRICE; FEINMAN, 2012) aponta a transição do Neolítico para as Idades dos metais como marco fundamental para encontrar as raízes das relações gregárias complexas e as suas distorções. O interessante é observar que, assim como o mesmo período histórico contém tanto o surgimento dos ritos de mascarados invernais como a potencialização dos elementos estruturais da diferenciação social, ambos sobreviveram de forma expressiva até a contemporaneidade. Essa pregnância pode ser observada nos estudos de Costa (COSTA, 2017), quando propõem um resumo histórico onde 
grandes câmbios sociais não destituem os ritos de um papel mais amplo quanto à ruptura do cotidiano pelos mascarados.

Destacamos no gráfico a seguir a passagem gradual da presença de aspectos religiosos para a perseguição de práticas místicas (Império Romano Cristão); a pulverização em diferentes modelos de festas que misturam a função profana e religiosa (Idade Média) e até um cenário híbrido contemporâneo, mas onde a maioria se revela como um festejo pagão, mesmo que dentro de calendários religiosos.

Percurso Histórico dos mascarados da Europa até as Américas

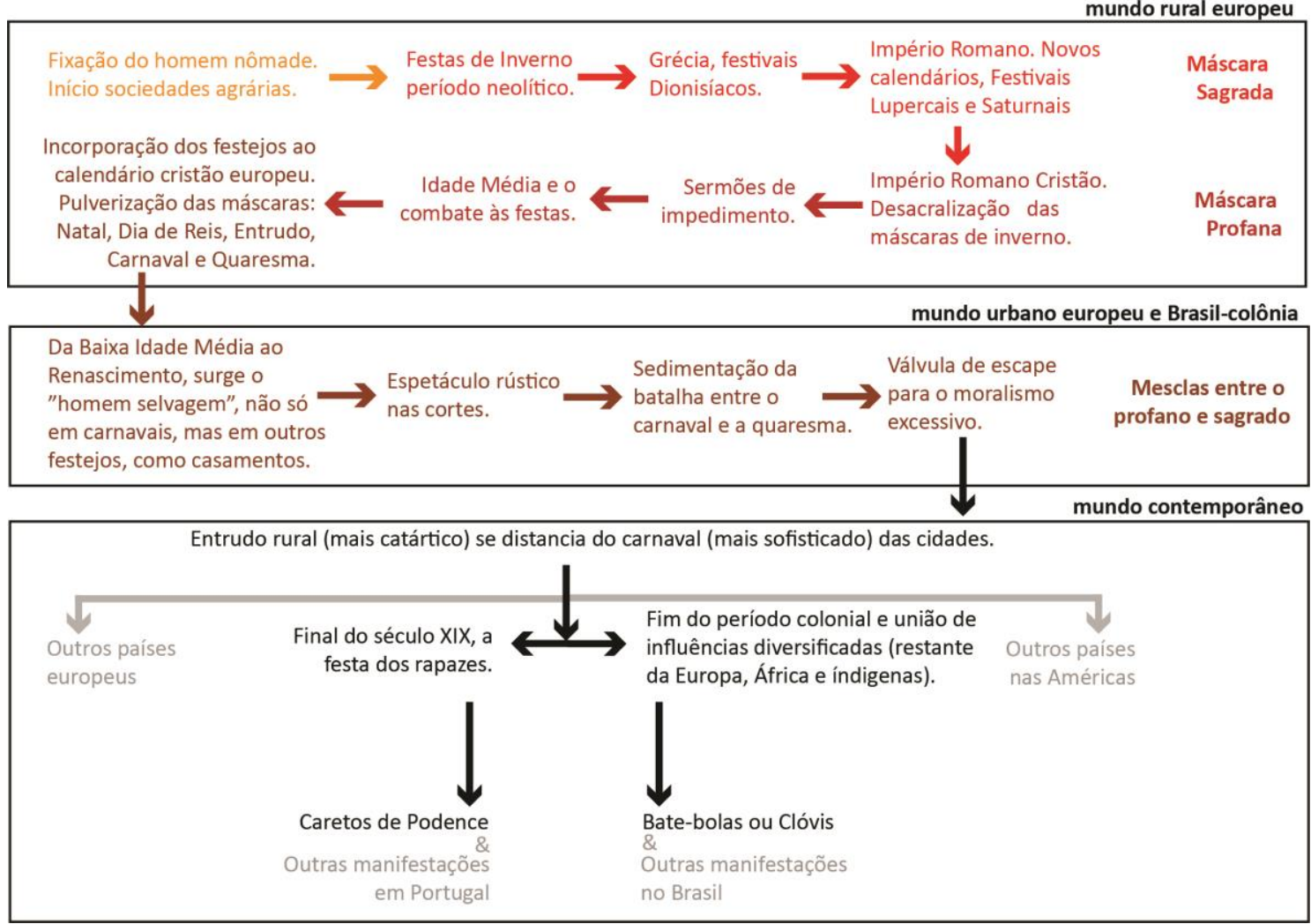

Figura 1: Percurso dos mascarados da Europa Neolítica à contemporaneidade na Europa e nas Américas - baseado parcialmente nos estudos de Costa (2017).

\section{Mascarados cariocas, a materialização de influências}

Para dar conta dessas relações históricas de transmissibilidade cultural, os festejos populares demandam estudos específicos por conta da natureza não institucional, marginal e, muitas vezes, sem documentação oficial sobre marcos de fundação ou mudanças. Desta forma, o estudo comparativo entre as manifestações contemporâneas é fundamental para entender não só as relações coloniais ou pós-coloniais diretas entres estes ritos, mas também, o seu valor arqueológico pela presença de rastros da história desta busca por reflexão sobre a identidade social e a singularidade individual simultaneamente.

Os estudos sobre desigualdade e diferenciação identitária apresentados na obra de Price (PRICE; FEINMAN, 2012) analisam a distinção gradual entre opressões dos sujeitos cometidas pelas hierarquias sociais e a diferenciação produtiva de indivíduos e grupos em atuações 
gregárias. No percurso da nossa linha do tempo, os modelos e sistemas dessa desigualdade são profundamente diversos, assim como os recursos usados pelas diferentes manifestações de mascarados. Para conhecer os Bate-bolas, vamos partir de sua inserção neste grande mapa historiográfico.

Os Bate-bolas ou Clóvis cariocas - oriundos da região de Santa Cruz na Zona Oeste de Cidade do Rio de Janeiro por volta da década de 1930/40 - emergem em um contexto particular de três marcos urbanos: a construção de uma ferrovia que ligava Santa-Cruz a Mangaratiba, o funcionamento do hangar alemão do dirigível Zeppelin e a existência no local do grande matadouro da cidade - todos eles ligados às influências migratórias no festejo.

A construção da ferrovia trouxe imigrantes de diferentes nacionalidades, como ibéricos, italianos e ingleses. Durante o governo Getúlio Vargas, nestas décadas, Santa Cruz cresceu com obras de saneamento e com o estímulo ao dinamismo econômico a partir da criação das colônias agrícolas que envolviam também o incentivo à imigração - incluindo um grande fluxo de europeus e japoneses. Além disso, o hangar do Zeppelin, na mesma época, trazia imigrantes alemães. O próprio nome, Clóvis, parece ter sido uma corruptela da palavra inglesa ou alemã "Clown" em função da denominação dada por imigrantes de ambas as línguas à fantasia que se assemelhava ao palhaço - pela roupa bufante e pelo tipo de desenho feito nas máscaras.

O matadouro contribuiu com as bexigas de boi que infladas serviam como as bolas que deram nomes aos personagens e que já eram tradição em festas europeias. $\mathrm{O}$ hangar e a cultura alemã contribuíram com um aspecto particular e muito importante da fantasia carioca, o material típico das máscaras: um telado de arame que era pintado com a ilustração do personagem e que prescindia de furos para olhos e respiração, mas, ao mesmo tempo, a transparência não permitia o reconhecimento do brincante. Tipo de material mais raro em máscaras, mas encontrada em manifestações alemãs como veremos adiante.

Não se pode precisar todas as manifestações que influenciaram mais ou menos diretamente os Bate-bolas, porém, como tantos outros ritos estrangeiros, ele acabou se tornando uma prática própria da cultura local com uma identidade particular. No entanto, pela análise das fantasias e do seu contexto de surgimento, podemos fazer aferições de proximidades mais diretas com os ritos ibéricos, as manifestações austro-húngaras e da Alemanha e interferências posteriores como as do carnaval de Veneza. Os bate-bolas recebem a influência de outros mascarados cariocas - como os demônios, caveiras e carrascos -; das escolas de samba e dos desfiles de fantasias de luxo do carnaval carioca; até chegar às influências mais atuais da indústria cultural de massa, das artes urbanas como o grafite e o hip-hop e o funk. A própria manifestação mudou na sua trajetória: de fantasia individual e chamada de "pirulito" do início até as fantasias de bujão ou as rodadas em saia e calça, já nos anos 1980 e 1990.

As fantasias passaram a ser usadas em turmas e com um tema que funciona como um enredo. A fantasia do tipo pirulito e individual hoje é mais usada por crianças e adolescentes - a exceção de turmas que resgataram a fantasia antiga evidenciando seu caráter de memória, já denominadas como "Retrô". A bexiga de boi passou a ser uma bola de plástico e existem hoje vários tipos de acessórios que substituíram ou convivem com a bola, tais como a sombrinha, os 
bichos de pelúcia e a bandeira. As substituições da bola foram, geralmente, uma alternativa para o estigma de violência do personagem.

Para este estudo, destacamos os dois tipos de fantasias de Bate-bolas mais frequentes, o pirulito e o "rodado e saia"2 e, neste artigo, vamos nos deter prioritariamente na análise formal das roupas e acessórios associados a aspectos mais gerais das performances. Para proceder a análise formal, colocaremos em diálogo os brincantes cariocas com seis manifestações ainda vigentes em seus países: os Krampus da Áustria ${ }^{3}$; os Tolos da Alemanha; os Busojarás na Hungria; os Caretos de Podence em Portugal e o Doutor da Peste e o Bauta de Veneza, na Itália que introduzimos nestas fichas organizadas pela pesquisa.

\footnotetext{
2 Denominamos aqui de 'Rodado e saia' para identificar os dois aspectos principais desse estilo, já que a nomenclatura desta roupa mais bufante ainda não é muito coincidente.

${ }^{3}$ Krampus na verdade é da região dos alpes e pode ser encontrado na Baviera, no sul da Alemanha e outras regiões rurais, além da Áustria. É possível encontrar a manifestação de Krampus no sul do Brasil, em Santa Catarina, no Vale do Itajaí em colônias alemãs.
} 

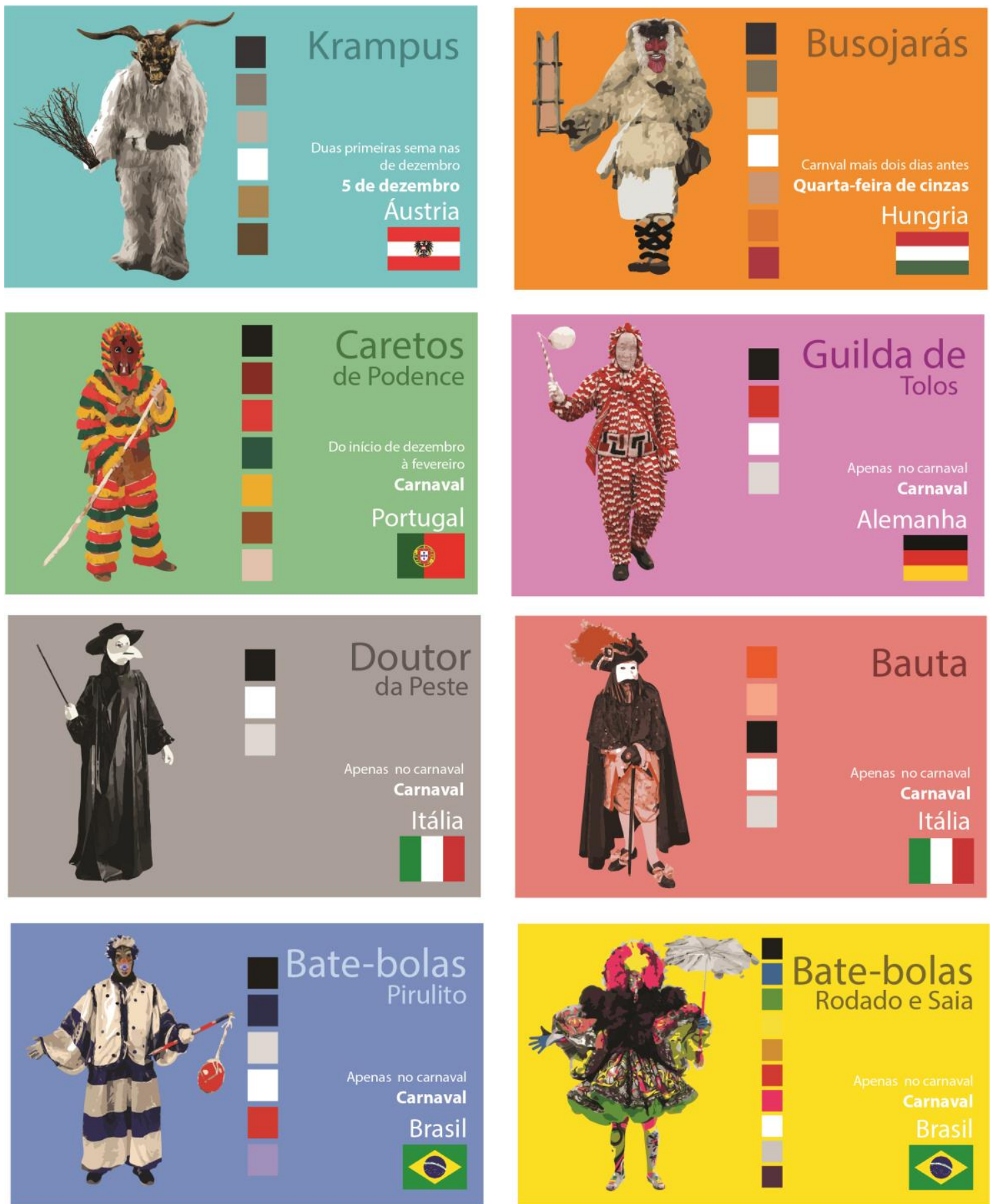

Figura 2: Catalogação dos personagens analisados neste estudo.

Abaixo, vemos um primeiro gráfico que une estas manifestações em um estudo comparativo que será analisado sobre diferentes aspectos, mas seguindo um fluxo de evidência de mudanças e apropriações formais entre as manifestações selecionadas. 


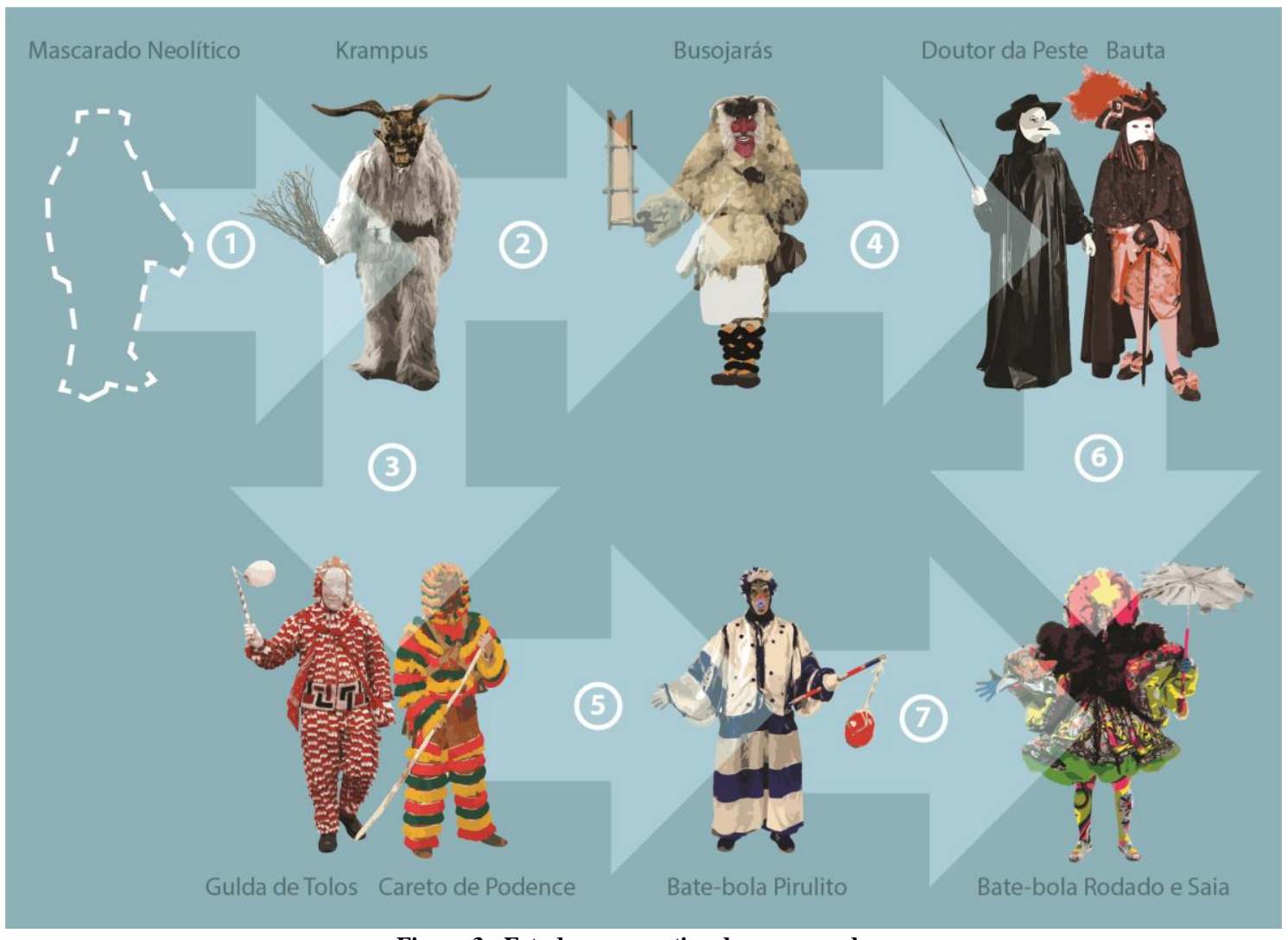

Figura 3: Estudo comparativo dos mascarados.

A ideia das setas e números não é indicar necessariamente um fluxo histórico cronológico, mas sim o fluxo de evidências materiais que contribuem para uma tipologia quanto ao aspecto proposto neste artigo - a dimensão material e performativa da ruptura com o cotidiano. Não há, naturalmente, registros do mascarado arcaico do Neolítico, mas os relatos históricos e arqueológicos apontam para a cobertura do corpo e rosto com peles animais e a descaracterização da identidade do brincante, tanto pela máscara, como pelo disfarce dos contornos corporais e o abandono de peças do vestuário e de acessórios comuns ao cotidiano.

Como vemos na figura 3, atualmente, o Krampus tem grande proximidade com as manifestações originais por ainda manter a cobertura densa de peles sobre o corpo, o uso de máscaras rústicas, sem material industrializado e com o uso de objetos naturais como galhos ou paus para a performance - elementos mais ligados à representação dos aspectos selvagem, animal e mágico. O Krampus acontece no período das festas denominadas Decembrinas por abrirem o inverno. Atualmente, ainda são uma mescla com os festejos católicos, pois as figuras acompanham o personagem São Nicolau que abre as comemorações natalinas. Assim como a ligação estética mais direta com o rito ancestral, sua proximidade com um rito religioso é muito maior do que os demais apresentados aqui.

Os Busojarás da Hungria inserem uma modificação ao mascarado arcaico, por misturar a ele mais elementos da cultura material das sociedades humanas, fundindo a figura transcendental com algumas peças do vestuário. As peles e as máscaras estão lá, mas agora se combinam com botas regionais, calças em estilo bombacha e bolsas típicas de trabalhadores rurais. Na mão, podem trazer uma matraca que produz sons estridentes e o que também identifica uma maior interferência da cultura civilizatória e de aparatos citadinos na construção do personagem, se 
comparados ao Krampus. Essas interferências acarretam também uma maior exposição da silhueta corporal, sejam nos pés e pernas ou nas mãos mais detalhadas com luvas. Simultaneamente, eles são mais distantes do papel religioso - lendas conectam a figura a fatos históricos da região com uma batalha contra o império otomano vencida por croatas mascarados que conseguiram salvar a cidade assustando os inimigos, por isso, a mistura de vestes de época e regionais. A ligação com fatos históricos típicos da Idade Média como guerras e doenças (Fim da Peste Bubônica no caso dos Tolos alemães ou dos Doutores da Peste de Veneza) substitui a descrição mágica de outros tempos.

Este eixo de números pares (2,4 e 6) que começam entre o Krampus e o Busojarás segue para diversas outras manifestações como o carnaval de Veneza, onde se acentua ainda mais o descolamento do disfarce do mascarado em relação ao homem invernal primitivo e seu personagem mais rústico e animal, para dar lugar aos novos personagens mais ligados às figuras que se apropriam de vestes rurais ou urbanas e que retratam grupos sociais humanos. Ainda há ruptura com hábitos, mas, agora, a fuga do cotidiano é porque as vestes remetem a outras épocas ou a exageros formais dos próprios vestuários citadinos e, prioritariamente, pela permanência da própria máscara. Aqui, destacamos apenas dois personagens masculinos do Carnaval de Veneza, mas são várias as personagens representadas neste festejo. O Doutor da Peste é uma figura real da Idade média que usava a máscara para proteger-se da contaminação pela doença e o Bauta ilustra um personagem ligado ao século XVIII em Veneza e, para tanto, representa vestes urbanas com todos os acessórios evidentes.

Nos números ímpares (3, 5 e 7), partimos da comparação entre o Krampus, o Careto de Podence e o Platzer ou Tolo da Alemanha. São muitas as relações dos Tolos e dos Caretos com os mascarados neolíticos e fica claro a arqueologia desta relação no confronto com os Krampus. Porém, os Caretos e os Tolos remetem ao mascarado invernal primitivo de forma apenas alegórica. A forma da roupa ainda objetiva cobrir todo o corpo e sem muitas relações com peças do vestuário, mas uma grande diferença se dará nos materiais. As peles do Krampus se tornam um franjado de lã ou escamas de tecido em cores vibrantes totalmente artificiais sem compromisso com a simulação fidedigna das cores de pelos animais - por isso, o destaque das paletas de cores nas fichas da figura 2.

Os Caretos trazem varas, gravetos e, mais raramente, bolas que servem para assustar os passantes. Já os Tolos alemães usam justo a bexiga inflada dos Bate-bolas. Apesar de um gorro estilizado dos Caretos e os cintos bordados dos Tolos, estes personagens se distanciam mais de uma figura primitiva e da floresta por conta de materiais manufaturados (franjas, escamas e colchas) e pigmentos puros (cores vivas) do que pela introdução de muitos elementos de peça do vestuário. Há, na verdade, uma indicação mais evidente da relação com padrões das vestes medievais e do renascimento - as faixas e cores vibrantes - e não pela modelagem de peças cotidianas.

$\mathrm{Na}$ adaptação que vemos no passo 5 - dos Caretos e dos Tolos para os Bate-bolas estilo pirulito -, a proximidade formal é muito perceptível. A primeira grande questão prática é que, agora, os festejos mudam de hemisfério. Se o carnaval em fevereiro comemora o fim do inverno europeu, no Brasil se dá em pleno verão. É óbvio que a primeira adaptação seria de materiais: no lugar da pele, escamas ou franjas de lã, são usados tecidos leves como o cetim. 
As faixas coloridas reaparecem na costura de tecidos diferentes em listras, aspecto forte que se mantém até nos outros estilos como os Bate-bolas estilo bujão ou rodado e saia. A bexiga de boi que dá origem ao nome dos Bate-bolas, por outro lado, mostra um laço muito mais arcaico do que o Busojarás ou o Krampus com o uso de vísceras animais para as ameaças ao público novamente mais próximos dos Tolos e dos Caretos. O odor e o aspecto escatológico da bexiga de boi ressequida e inflada talvez sejam o que há de mais rústico na fantasia - o que se manteve até o início dos anos 1980, onde foi substituída por bolas de plástico, novamente uma alegoria formal que se vale da mudança de materiais naturais para industrializados. Os Bate-bolas do tipo pirulito poderiam ter apenas o macacão bufante semelhante à forma difusa dos dois anteriores, mas, aos poucos, incorporaram capas ou coletes - peças de vestuário que se associavam gradativamente ao personagem, mas que não eram fundamentais. $\mathrm{Na}$ imagem da figura 3, já podemos ver um do estilo pirulito mais contemporâneo e já com colete e bola de plástico.

As máscaras originais misturavam figuras assustadoras com referências às maquiagens do palhaço. Surge também máscaras como a denominada de "Quilingue" por ser a imagem de uma caveira com a palavra "Killing" escrita em estêncil na testa. A pelúcia que fazia o cabelo, por vezes, virava barba e bigode, criando máscaras ainda mais antropomorfizadas. Essas primeiras manifestações dos pirulitos são integralmente profanas - fora o respeito ao calendário oficial católico do carnaval. A dimensão lúdica está presente no anonimato do mascarado e nos riscos encenados pelas ameaças feitas ao e pelo personagem - a sua grande função brincante também conectada com os festejos Neolíticos.

Desde os anos 1990, a manifestação mais frequente nos subúrbios é a fantasia rodada e que usa saia ao invés de calça. Esta fantasia serve indistintamente a Bate-bolas que usam bolas, bonecos ou sombrinhas. Hoje, existem mais de 700 turmas entre as que foram cadastradas pela pesquisa de doutorado de Monique Bezerra da Silva - ainda em andamento -, e as turmas podem ter de três a centenas de integrantes e as fantasias podem custar mais de 3.000 reais cada unidade. A manifestação gerou hoje uma cadeia produtiva extensa que também estamos mapeando na pesquisa e que é responsável pela explosão de interferências formais e de materiais inovadores.

Pelo passo 7, podemos chegar aos Bate-bolas do estilo rodado e saia como uma evolução das interferências iniciadas nos Caretos e nos Tolos. A paleta de cores explode em uma miríade de possibilidades, o uso de materiais incorpora agora tecidos sintéticos, plástico, malha, pedraria, plumas e até luzes de LED.

Além da mudança cromática e de materiais, a forma da roupa e a introdução de elementos figurativos do vestuário também é acentuado, por isso, a colaboração também do fluxo de passos pares (passo 6) que envolve a introdução crescente de vestes estruturadas. O colete ganha importância e passa a ser chamado de casaca, pois aumenta e serve de suporte para a representação das ilustrações que remetem aos enredos. As mangas e pernas da calça ficam mais bufantes e são elevadas para dar este efeito deixando mais à mostra as meias, os calçados e as luvas - podendo se relacionar a alguns tipos de Bauta. O passo 6 aponta um fato particular neste estilo de Bate-bola: os calçados ganham destaque. Ou são customizadas junto com a fantasia, ou são tênis de marcas famosas e de alto custo que são de cores vibrantes como as roupas e 
ostentados como um desejo de consumo dos próprios brincantes - os jovens de periferia do Rio de Janeiro.

As relações dos Bate-bolas com o consumo são tantas que seus temas geralmente são de personagens da indústria cultural de massa; os acessórios podem ser produtos licenciados e industrializados sobre esses personagens; desenvolvem marca da turma e processos de divulgação do enredo e também criam um "kit" de produtos para cada desfile que incluem um uniforme para ser usado sob a fantasia, canecas para bebidas ou outros acessórios customizados com a marca da turma e o tema do ano.

As meias e as luvas são agora customizadas e decoradas em complexos patchworks de malhas em cores vibrantes - que podem ser usados também nos capuzes das máscaras. A pintura da máscara pode remeter aos palhaços originais, mas atualmente devem ser referentes aos temas e podem, por isso, trazer estilos tão distintos de traços como do Mangá, dos desenhos animados ou do grafite. $\mathrm{O}$ uso de purpurina, materiais brilhantes, pedrarias e diversos tipos de acabamentos remetem claramente a interferência de mascarados como os de Veneza, onde a fantasia é quase um exagero das vestes de luxo, mas também à liberdade de materiais do fluxo de números ímpares.

Recebendo também fortes influências da grande indústria carnavalesca do Rio de Janeiro em torno das Escolas de Samba, os Bate-bolas cariocas são uma mistura muito particular de uma figura grotesca e bestial naturalmente relacionada ao mascarado primevo - o que se preserva pelo uso das máscaras assustadoras e da bexiga - e, por outro lado, as interferências de personagens de carnavais de rua e de baile que são mais urbanizados e adereçados com o vestuário e a manufatura. A dimensão profana ainda se mantém como mais expressiva, porém, agora que a fantasia passou de um rito individual para a realização em turmas, ganhou algumas interferências religiosas como: ter como padroeiro um santo católico, ilustrar figuras santas nas fantasias como forma de promessas ou homenagens, evocar orações no momento da saída, nas proibições ao uso de máscaras em determinados momentos das religiões de matriz africana e até no preconceito e perseguição por membros de religiões neopentecostais em algumas localidades.

A performatividade é outra questão que vem mudando muito nos Bate-bolas. A espetacularização dos Bate-bolas coloca em risco a sua natureza brincante por vários motivos, mas o principal é que algumas saídas de turmas hoje podem se assemelhar mais a desfiles do que às troças dos outros mascarados, ou dos próprios Bate-bolas do tipo pirulito. $\mathrm{O}$ eixo 6 que passa pelo carnaval de Veneza, não traz só a dimensão formal, mas também, a influência na dimensão performativa. O carnaval de Veneza é quase uma exposição de esculturas belíssimas a serem contempladas. Sem a ação de assustar e sem a dança, o desfile de roupas valoriza muito mais o sublime da estética do que a performance brincante. Os bate-bolas ainda são dançantes e movimentados, mas perdem aos poucos a brincadeira de gerar medo e se tornam fantasias monumentais - que já provocam estranhamento pelo volume, luxo e riqueza de detalhes formais. A relação do espetáculo das Escolas de Samba com as estruturas mais livres dos blocos de rua também pode ajudar a pensar nesta mudança de papel dos Bate-bolas atuais. 
O resultado final destas relações entre vestes e os festejos é que a função de ruptura com o cotidiano como forma de dar visibilidade a certas amarras dos papéis sociais desiguais é conduzida de diferentes formas, mas com algumas semelhanças que confirmam os laços históricos. Há uma ampliação de um caráter cômico e cotidiano em ambos os eixos (ímpar e par), que naturalmente afasta da representação de seres mágicos e sagrados. Talvez, em uma sociedade mais ligada a princípios anímicos, a catarse coletiva seja mais identificada com a representação de formas primitivas, demoníacas e animais. Nas sociedades cada vez mais urbanizadas e mais distantes dos ritos sagrados e mágicos, a figura disparadora da catarse pode ser muito mais o humor satírico analisado por Mikhail Bakhtin nos carnavais medievais (BAKHTIN, 1987). A figura 1 lembra que a passagem gradual da máscara sagrada para a profana no Império Romano talvez tenha requerido a ampliação da função de sátira do cotidiano como forma de expurgo, antes vivido por um personagem mágico. Música, dança, sexualidade e substâncias entorpecentes seguem neste esforço de substituir a catarse da fé pela catarse atual que se abstém da crença religiosa do rito.

A presença ou não de peças do vestuário, portanto, não prejudica diretamente à ruptura. Seja com um papel mais religioso ou mais profano, a experiência do sujeito diante da própria máscara já é disruptiva. Há uma alteração do cotidiano pela própria presença da máscara. Ambos os fluxos, o dos números pares (com crescente representação do vestuário) ou ímpares (com crescente valorização de materiais e resultados estéticos artificiais) se sobrepõem (há inovação material ao ampliar peças do vestuário) e colaboram para este diálogo histórico.

A potência da máscara de relativizar o cotidiano coletivo, a identidade individual e a percepção da realidade está lá, presente nos Bate-bolas cariocas. O que faço, o que represento e como percebo o que faço e o que represento são anualmente colocados em cheque também na periferia da cidade do Rio de Janeiro.

\section{Conclusões}

A análise cruzada entre diferentes manifestações de mascarados atuais permite identificar que as funções primordiais do rito são realmente muito pregnantes apesar de tantos desvios. Além disso, este primeiro mapa de papéis e expressões serve para identificar como aspectos formais, funcionais, simbólicos, performativos e de materiais podem colaborar para o estudo dos signos discursivos inarticulados que são reificados ou alterados nos festejos contemporâneos. Entre os aspectos levantados da análise formal e performativa dos ritos, destacamos:

- níveis de implicação com hábitos religiosos ou profanos;

- representação de personagens mais transcendentes ou satíricos;

- acessórios mais primitivos ou mais ligados a hábitos citadinos;

- presença de elementos do vestuário cotidiano;

- tipos de estilização destes elementos (vestuário e acessório);

- uso de materiais naturais ou manufaturados; 
- tipo de palheta cromática mais ligada a tons da natureza ou mais artificiais;

- recursos para esconder a identidade fisionômica do brincante e a sua silhueta corporal;

- relevância da presença do medo ou do humor;

- estilo de performance brincante ou de desfile;

- interferência da cultura do espetáculo e da indústria cultural massificada;

Estas dualidades não são estanques, oferecem apenas algumas tensões para uma análise crítica construindo um primeiro conjunto de parâmetros onde estudos mais aprofundados de materiais, processos produtivos, sustentabilidade econômica e social, custos, performatividade, simbolismos e recepção social podem implicar mais diretamente a área da análise visual no aprofundamento do estudo etnográfico destas e outras manifestações.

\section{Referências}

BAKHTIN, M. A Cultura Popular na Idade Média e no Renascimento. Brasília: Universidade de Brasília, 1987.

CHANG, K.-C. Study of the Neolithic Social Grouping: Examples from the New World. American Anthropologist, p. 298-334, 1958.

COSTA, L. F. Caretos de Podence - História, Patrimônio e turismo. Braga: Poética Edições, 2017.

PRICE, T. D.; FEINMAN, G. M. Pathways to Power - New Perspectives on the Emergence of Social Inequality. Nova York: Spinger, 2012.

\section{Nilton Gonçalves Gamba Junior}

Coordenador do DHIS - Laboratório de Design de Histórias do Programa de Pós-graduação em Design do Departamento de Artes e Design da PUC-Rio. Possui graduação em Desenho Industrial com habilitação em Programação Visual pela Escola de Belas Artes da UFRJ (1993), mestrado em Design pela PUC-Rio (1999) e doutorado em Psicologia (Psicologia Clínica) pela PUC-Rio (2004). Atualmente é professor do Departamento de Artes e Design da PUC-Rio. gambajunior@puc-rio.br

\section{Priscila Andrade Silva}

Atualmente faz doutoramento em Design pela PUC-Rio. Mestre em Design pela PUC-Rio, com dissertação sobre o trabalho de Zuzu Angel. Especialista em História da Arte e Arquitetura do Brasil pela PUC-Rio. Graduada em Desenho Industrial pela Escola Superior de Desenho Industrial - ESDI e Graduada em Moda pela Universidade Veiga de Almeida - UVA. É professora na graduação em Design na PUC-Rio. Além disso, é sócia fundadora da Zellig. priscila.a.andrade@gmail.com 